\section{Cahiers de Narratologie}

Analyse et théorie narratives

$35 \mid 2019$

Le style comme événement

\title{
Auraix-Jonchière, Pascale, Voix poétiques et mythes féminins
}

Sara Calderon

\section{(2) OpenEdition}

Journals

Electronic version

URL: http://journals.openedition.org/narratologie/9229

DOI: 10.4000/narratologie.9229

ISSN: 1765-307X

Publisher

LIRCES

\section{Electronic reference}

Sara Calderon, «Auraix-Jonchière, Pascale, Voix poétiques et mythes féminins », Cahiers de Narratologie [Online], 35 | 2019, Online since 03 September 2019, connection on 24 September 2020. URL : http://journals.openedition.org/narratologie/9229; DOI : https://doi.org/10.4000/narratologie. 9229

This text was automatically generated on 24 September 2020.

Article L.111-1 du Code de la propriété intellectuelle. 


\title{
Auraix-Jonchière, Pascale, Voix poétiques et mythes féminins
}

\author{
Sara Calderon
}

\section{REFERENCES}

Aurais-Jonchière, Pascale, Voix poétiques et mythes féminins, Clermont-Ferrand, Presses Universitaires Blaise Pascal, 2017

1 Pascale Auraix-Jonchière est déjà reconnue pour ses travaux sur la représentation faite par la littérature de figures mythiques féminines majeures, telles que Lilith. Ce volume collectif, qu'elle coordonne, reprend une partie des préoccupations qui l'ont habitée en tant que chercheure pour s'appliquer à produire une réflexion d'ensemble sur les liens existants entre les représentations que la littérature a pu faire de figures mythiques et leur dimension métapoétique.

2 En effet, le volume axe ses préoccupations sur les voix poétiques : il s'applique donc à entendre s'exprimer les personnages féminins, que ce soit de façon directe ou par le biais de médiateurs. Cependant, l'irruption dans le texte de ces voix féminines est porteuse d'un sens qui révèle la nature et la facture du texte, le transforme, éventuellement. Le volume s'intéresse ainsi au "poétique» au sens large, au "poétique » compris comme mode de pensée et d'écriture. Il aborde le traitement donné aux figures mythiques féminines en tant qu'elles sont moteur de réflexion métalittéraire et induisent une forme de poésie, elle aussi comprise au sens large du terme.

3 A la manière de ce qui se passe en linguistique, les voix sont donc envisagées dans le volume comme "archimythèmes", c'est-à-dire, comme point d'intersection de différents mythes; comme expression d'un noyau symbolique commun. Elles sont d'ailleurs étudiées dans des textes classiques et dans des textes contemporains, 
beaucoup d'articles traitant des corpus allant au delà d'une seule œuvre ou d'un seul auteur.

4 L'ouvrage s'articule ainsi en quatre parties et un épilogue. La première partie, "Confrontation et glissement des voix», est consacrée aux figures féminines qui substituent leurs voix à celle de l'autre, dans une perspective créatrice. Cette première partie étudie les différents relais ou glissements que cette substitution peut nécessiter ou mettre en place. Elle est occupée par les figures d'Eve, de Lilith, et par la Perséphone de Gide.

5 La deuxième partie, "La voix des sirènes : chant et charme ", se concentre sur la figure de la sirène, omniprésente dans la poésie de fin-de-siècle. La partie explore la représentation de ces créatures qui, outre leur contenu mythique, ont ouvert à tant de réappropriations et de fantasmes. Elle ouvre parfois en conséquence à des perspectives gnoséologiques et prophétiques.

6 La troisième partie, intitulée "Les potentialités tragiques de la voix », se concentre sur les modulations de la voix, celle-ci se muant parfois en cri de douleur. Pour cette partie, la figure mythique phare est celle de Cassandre.

7 Dans la quatrième partie de l'ouvrage, c'est le corps entier qui se fait voix. Elle porte ainsi le titre "Gestuelle et création » et se consacre à Salomé, souvent représentée en train de danser, et aux Néréides, qui personnifient, elles, le mouvement des vagues.

L'épilogue, "Entre ombres et lumières: les voix féminines dans les Métamorphoses ", explore la façon dont les figures féminines que l'on peut trouver dans les Métamorphoses d'Ovide sont inductrices de poésie et disent, tout à la fois, ce qu'est pour Ovide la poésie. Les Métamorphoses ont ceci de particulier qu'elles se fondent sur l'articulation entre les passions des âmes et les métamorphoses des corps, et qu'elles font correspondre leur sujet, la métamorphose, et la forme, une écriture de la variation. Etablissant une typologie qui comprend les amoureuses, les magiciennes et les poétesses, Hélène Vial explore ainsi la manière dont les figures féminines, par le lien qu'elles établissent à la voix (qu'elles perdent au cour des métamorphoses et qu'elles regagnent parfois) et au langage (car la magie en est un) peuvent être lues, dans une perspective métapoétique, comme vecteur privilégié d'expression du poète en ce qui concerne son propre art de création. De par son caractère global, pour ce qui est des voix de figures mythiques, l'article clôt très bien un ouvrage d'exceptionnelle richesse réflexive pour ce qui est des liens qu'entretient le féminin, par l'intermédiaire des différentes figures féminines, au principe créatif et comment il peut parfois le personnifier.

9 Malgré la thématique choisie, l'avant-propos déclare explicitement que le volume n'a pas vocation à l'envisager sous l'angle du gender. Il ne souhaite pas analyser les voix traitées en tant que voix sexuées, pas plus que déceler une hiérarchie des sexes. Sans enlever son mérite à ce volume passionnant, il serait possible d'objecter que, précisément parce que la plupart des auteurs sont des hommes, et choisissent le plus souvent des narrateurs masculins, mais occupés par des mythes féminins, il eût été intéressant de ne pas se passer de cet angle d'analyse qui, sans se substituer à l'approche choisie, aurait permis de mettre en lumière comment l'instance énonciatrice hégémonique énonce une altérité. Ce d'autant plus que, dès l'avantpropos, l'on précise qu'il semble possible de dégager des modalités d'expression 
singulières, inhérentes au féminin, lorsqu'il s'agit pour ces personnages de devenir « voix poétiques ».

10 Une perspective de genre aurait sans doute permis d'introduire des interrogations supplémentaires sur la raison de faire de figures féminines l'expression de la poésie ou, pour la première partie, sur la mesure dans laquelle une voix qui reste masculine peut parler à travers d'une figure féminine honnie et bâillonnée pour exprimer un contrepoint, sur la possibilité même d'un contre-discours. Il n'en demeure pas moins que l'ouvrage reste passionnant, et déjà très intéressant par son approche, qui ne consiste pas à envisager ces figures comme objet, comme muse, mais comme sorte de porteparole ou d'alter ego du créateur, une approche déjà très riche d'interrogations. 